\title{
EKSPLORASI AKUIFER AIR BAWAH TANAH MENGGUNAKAN METODE TAHANAN JENIS 2D DI DESA SELARU KABUPATEN KOTABARU, KALIMANTAN SELATAN
}

\author{
Rudy Hendrawan Noor ${ }^{1)}$, Ishaq ${ }^{1)}$, Jarwanto ${ }^{1)}$, dan Dwi Priono ${ }^{2)}$ \\ ${ }^{1}$ Jurusan Teknologi Pertambangan, Akademi Teknik Pembangunan Nasional (ATPN) Banjarbaru, \\ Jl. Taman Gembira Barat No.14 GuntungPaikat, kodepos 70711 \\ ${ }^{2}$ Dinas Energi dan Sumber Daya Mineral, Provinsi Kalimantan Selatan, \\ Jl.Pangeran Suriansyah No 7, kodepos 70711 \\ Email: rudyhendrawan28@gmail.com; ishaqitb14@gmail.com
}

\begin{abstract}
Geoelectric resistivity method is one method that can be used to characterize water-bearing rock layers (aquifers). This method is based on the existence of differences in type resistivity in the layers of rock that are flowed electrically. The use of this method is based on easy application, faster data acquisition with broad data coverage (lateral and vertical), and lower costs. Data acquisition uses two configurations or electrode arrangement, namely sclumberger and wenner-schlumberger configurations. The number of trajectories for data acquisition uses one path with a total of 28 electrodes and the spacing between the electrodes is 20 meters. The data obtained in the form of data resistivity type of each underground layer and its depth will be further analyzed using AGISSAdmin software. The results are obtained in the form of a 2dimensional (2D) cross-sectional value of underground layers laterally and vertically. The low resistivity value will be interpreted as a layer containing ground water, which was previously corrected against the geological and hydrological data of the area. From the cross section of the type resistors, values of 20 - 317 $\Omega \mathrm{m}$ were obtained for the wenner and wenner-schlumberger arrangements. Selaru Village consists of two rocks unit, the first rock $(\leq 120 \mathrm{Ohm} . \mathrm{m})$ in the form of Tanjung Formation rocks, with large porosity and small permeability and groundwater potential in this unit is small $(0-40 \mathrm{~m}$ depth). The second rock ( $\geq 120$ Ohm.m) is Pre Tertiary, with very little porosity and permeability, except secondary porosity in rock fractures.
\end{abstract}

Keywords: geoelectric, groundwater, wenner, wenner-schlumberger

\section{PENDAHULUAN}

Usaha untuk memanfaatkan dan memperoleh air telah dilakukan sejak dahulu. Salah satu cara untuk memperolehnya dengan menggali sumur, namun dengan berbagai keterbatasan sumur gali sudah mulai ditinggalkan dan perkembangannya mengarah kepenggunaan sumur-sumur bor dengan kedalaman tertentu. Baik pembuatan sumur gali dan sumur bor banyak dilakukan tanpa mengetahui keterdapatan, posisi dan ketebalan lapisan pembawa air (akuifer) di bawah permukaan bumi. Dengan cara tersebut maka tidak menutup kemungkinan sumursumur yang dibuat tidak berisi air karena tidak menembus lapisan akuifer. Kasus ini umumnya terjadi terutama pada daerah yang sulit air.
Desa Selaru berada pada Kecamatan Pulau Laut Tengah di Kabupaten Kotabaru, Kalimantan Selatan adalah salah satu daerah yang ketersediaan air sulit terutama pada musim kemarau. Pemanfaatan air bersih oleh penduduk banyak bersumber dari air permukaan (air sungai) yang ada di desa tersebut, namun pada musim kemarau ketersediaan air menjadi minim bahkan keruh, sehingga tidak layak lagi untuk dimanfaatkan sebagai air bersih. Maka dari itu diperlukan usaha untuk mencari sumber air alternatif.

Guna memenuhi kebutuhan air bersih penduduk Desa Selaru, maka diperlukan usaha untuk memperoleh sumber-sumber air bersih. Salah satu sumber yang mudah dan dapat dimanfaatkan adalah 
sumber air tanah. Namun, tidak semua daerah di bawah tanahnya mengandung air tanah, dikarenakan adanya perbedaan karakteristik batuan terhadap kemampuan penyimpanan air, sehingga diperlukan penyelidikan terlebih dahulu untuk mengetahui keterdapatan lapisan-lapisan batuan yang mengandung air tanah (akuifer) serta kedalamannya dengan harapan nantinya dapat dimanfaatkan oleh penduduk setempat.

Meskipun air tanah tidak dapat secara langsung diamati melalui permukaan, penyelidikan permukaan merupakan langkah awal yang cukup penting dilakukan, paling tidak dapat memberikan suatu gambaran mengenai lokasi keberadaan air tanah tersebut.

Beberapa metode penyelidikan permukaan tanah yang dapat dilakukan, diantaranya: metode geologi, metode gravitasi, metode magnit, metode seismik, dan metode geolistrik. Dari metode-metode tersebut, metode geolistrik merupakan metode yang banyak sekali digunakan dan hasilnya cukup baik (Bisri,1991). Penggunaan metode ini didasari pada penerapan yang mudah, perolehan data yang lebih cepat dengan cakupan data yang luas, serta biaya yang lebih murah. Metode geolistrik didasari dengan adanya perbedaan tahanan jenis pada lapisan-lapisan batuan yang dialirkan arus listrik.
Tujuan penelitian ini, yaitu untuk memperoleh gambaran lapisan-lapisan batuan bawah permukaan berdasarkan perbedaan tahanan jenisnya, sehingga dapat diklasifikasikan sebagai lapisan pembawa air (akuifer), serta dapat diketahui kedalaman dan ketebalannya sehingga dapat menentukan lokasi titik bor air tanah. Seperti diketahui tahanan jenis air tanah bervariasi dari 10 hingga 100 ohm.m, tergantung pada konsentrasi garam terlarut (Loke, 2004). Dengan cara ini bisa ditetapkan lokasi rencana dari titik-titik pengeboran sumur bor yang diharapkan mampu untuk menghasilkan air dalam jumlah yang boleh dikata cukup berarti, jika kondisi lapangan memang mendukung hal tersebut.

\section{METODE PENELITIAN \\ Lokasi Penelitian}

Lokasi penelitian dilakukan di Desa Selaru Kecamatan Pulau Laut Tengah, Kabupaten Kotabaru, Provinsi Kalimantan Selatan. Berkisar $\pm 300 \mathrm{~km}$ kearah timur dari kota Banjarmasin, Ibu Kota Kalimantan Selatan. Garis merah merupakan kumpulan titik-titik pengukuran di lapangan yang membentuk garis lurus. Lintasan geolistrik diukur di pinggiran jalan Desa dan sebagian titik pengukuran terletak di kebun karet untuk memperoleh lintasan geolistrik yang lurus.

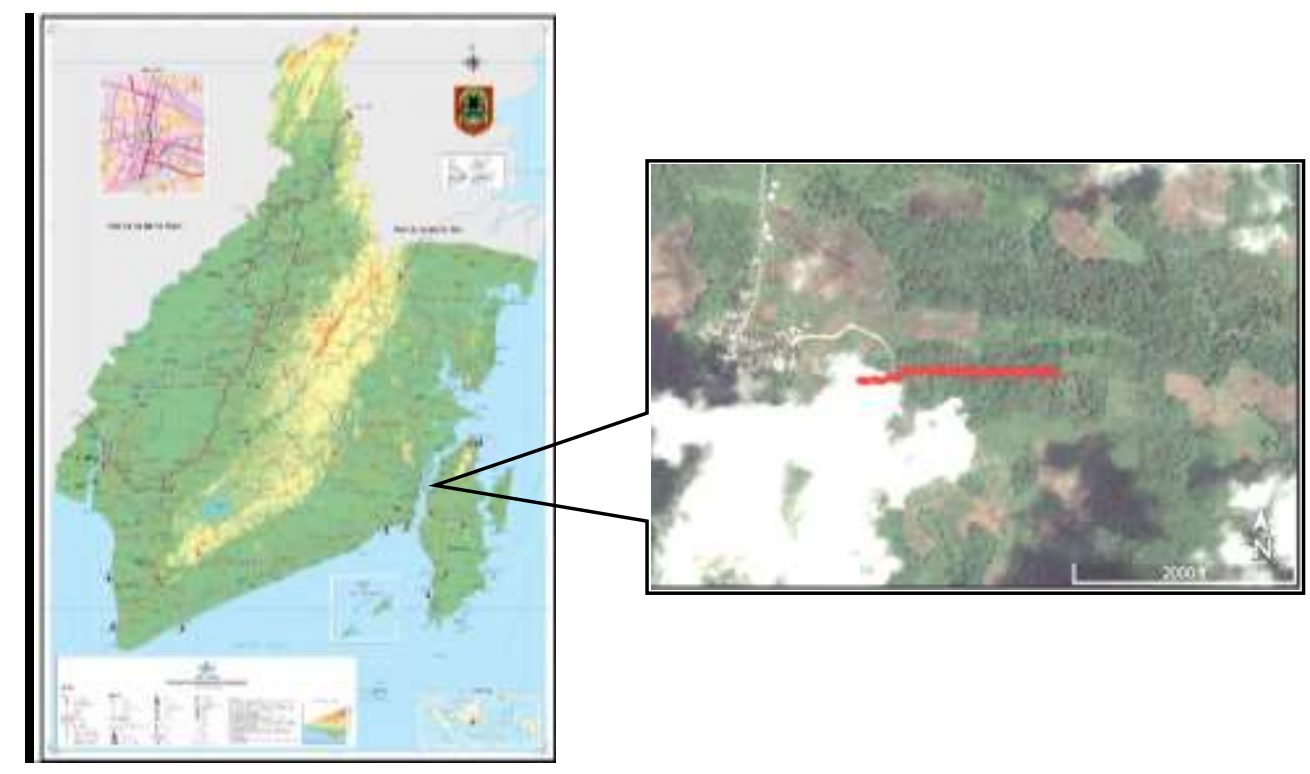

Gambar 1. Peta Lokasi Penelitian 


\section{Akuisisi Data dan Metode}

Jenis penelitian berupa penyelidikan lapangan secara langsung dengan menggunakan metode Geolistrik. Data yang digunakan pada penelitian ini berupa data primer dimana perolehan data diakuisisi langsung di lapangan. Metode akuisisi data menggunakan dua konfigurasi atau susunan elektroda yaitu konfigurasi sclumberger dan wennerschlumberger (gambar 3). Namun jumlah lintasan untuk akuisisi data menggunakan satu lintasan dengan jumlah elektroda sebanyak 28 buah dengan spasi antara elektroda adalah 20 meter.

Sebelum pengambilan data, terlebih dahulu diawali survei lapangan untuk menentukan titik lintasan pengambilan data, mengingat bentangan lintasan pengambilan data geolistrik diperlukan lintasan yang lurus dengan harapan data yang diperoleh lebih akurat.

Proses pengambilan data dilakukan dengan menggunakan alat geolistrik Supersting R1/IP dengan akuisisi data menggunakan dua konfigurasi, yaitu konfigurasi wenner dan wenner-schlumberger. Data yang diperoleh berupa data tahanan jenis masing-masing lapisan bawah tanah dan kedalamannya yang akan dianalisis lebih lanjut dengan menggunakan software AGISSAdmin. Hasil pengolahan data berupa tampilan 2 dimensi (2D) lapisan-lapisan permukaan bawah bumi secara lateral dan vertikal yang menunjukkan nilai-nilai tahanan jenis dan kedalamannya. Nilai tahanan jenis yang rendah akan diinterpretasikan sebagai lapisan yang mengandung air tanah. Selain menggunakan referensi tahanan jenis, juga digunakan analisis berdasarkan peta geologi dan peta hidrogeologi di daerah penelitian.

Setiap elektroda yang ditancapkan di permukaan akan diukur masing-masing koordinatnya dengan menggunakan GPS (Globale Position System), selain tujuannya mempermudah diplot pada peta juga untuk melihat elevasi permukaan sehingga dapat mengoreksi kedalaman akuifer dari permukaan. Secara ringkasnya alur

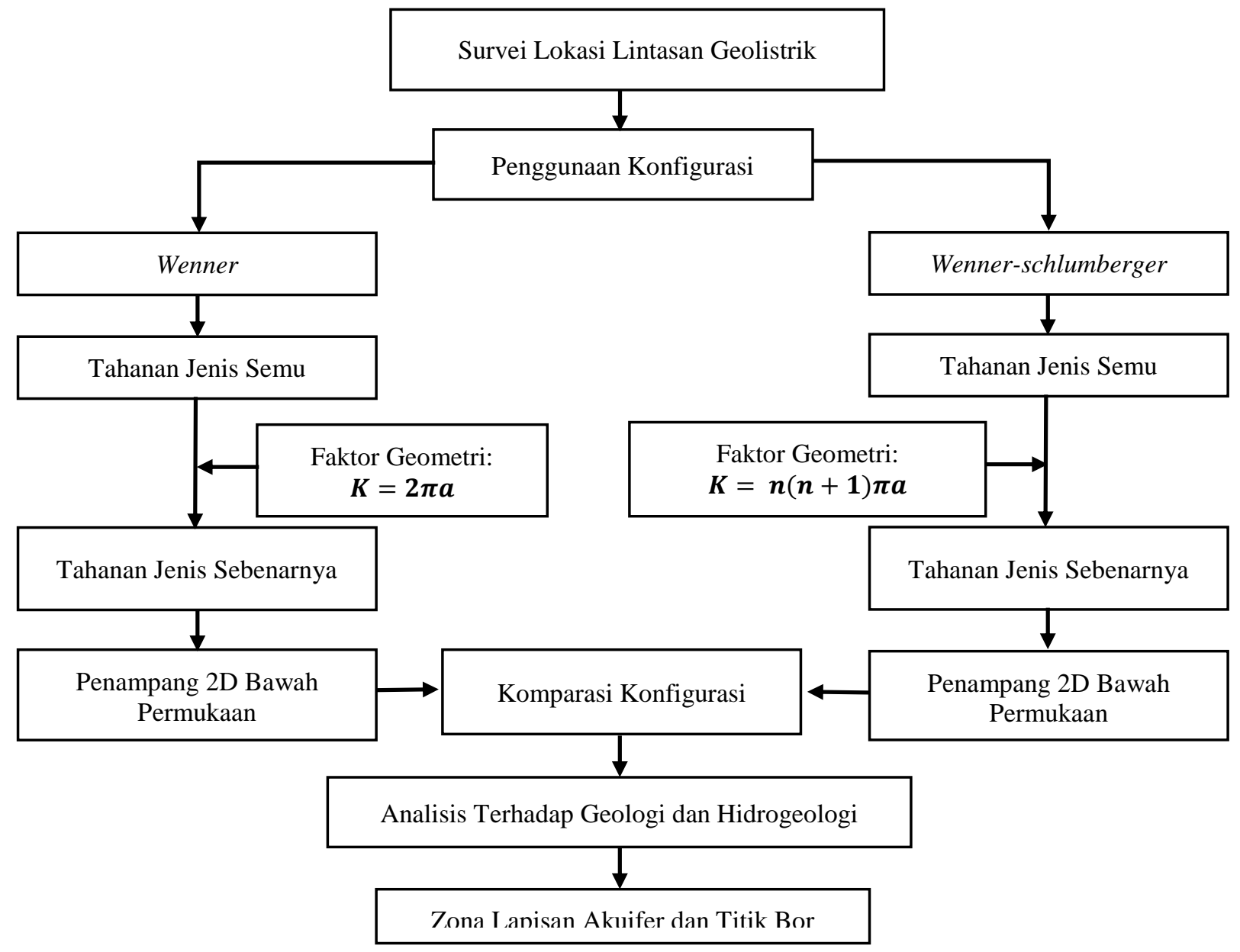

Gambar 2. Flowchart Penelitian 
penelitian ini dapat dilihat pada gambar 2:

\section{Susunan Eletroda Arus dan Potensial}

Pada setiap titik pengukuran tahanan jenis digunakan empat elektroda, dengan dua elektroda arus ( $\mathrm{C} 1$ dan $\mathrm{C} 2)$ dan dua elektroda potensial (P1 dan P2). Dua elektroda arus yang dipasang dengan jarak tertentu seperti pada Gambar 3, akan menyebabkan potensial pada titik-titik dekat permukaan dipengaruhi oleh kedua elektroda arus tersebut. Adanya deteksi perbedaan potensial ini akan dikonversi sebagai tahanan jenis di setiap lapisan bawah tanah.

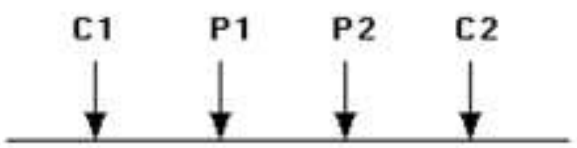

Gambar 3. Susunan empat elektroda pengukuran tahanan jenis di permukaan tanah.

Beda potensial antara P1 dan P2 dapat ditulis sebagai berikut :

$\Delta V=\frac{\rho I}{2 \pi}\left(\frac{1}{r_{\mathrm{C} 1 \mathrm{P} 1}}-\frac{1}{r_{\mathrm{C} 2 \mathrm{P} 1}}-\frac{1}{r_{\mathrm{C} 1 \mathrm{P} 2}}+\frac{1}{r_{\mathrm{C} 2 \mathrm{P} 2}}\right)$

dengan faktor geometri:

$\mathbf{k}=\frac{2 \pi}{\left(\frac{1}{r_{\mathrm{C} 1 \mathrm{P} 1}}-\frac{1}{\mathrm{r}_{\mathrm{C} 2 \mathrm{P} 1}}-\frac{1}{r_{\mathrm{C} 1 \mathrm{P} 2}}+\frac{1}{\mathrm{r}_{\mathrm{C} 2 \mathrm{P} 2}}\right)}$

Maka persamaan (1) dapat ditulis menjadi

$\boldsymbol{\rho}=\mathbf{k} \frac{\Delta \mathbf{V}}{\mathbf{I}}$

dengan $\mathrm{I}$ arus dalam ampere, $\Delta \mathrm{V}$ beda potensial dalam volt, $\rho$ resistivitas (tahanan jenis) dalam ohm meter dan $\mathrm{k}$ merupakan faktor geometri dari konfigurasi elektroda potensial dan elektoda arus dalam meter (Loke, 2004).

Secara umum untuk semua konfigurasi di dalam metode geolistrik, menentukan besaran tahanan jenis $(\rho)$ di masing-masing titik pengukuran elektroda, yaitu dengan menggunakan persamaan 3 di atas. Namun, yang membedakan hasil analisa pada setiap konfigurasi adalah adanya perbedaan faktor geometri (k). Pada penelitian ini menggunakan dua konfigurasi dalam pengukuran tahanan jenis, yaitu konfigurasi wenner dan konfigurasi wenner-schlumberger. Eksplorasi lapisan akuifer air tanah pada umumnya menggunakan metode sounding vertical dengan konfigurasi schlumberger. Konfigurasi ini memiliki penetrasi yang bagus secara vertikal, namun hasil analisa yang diperoleh cuman berupa 1 dimensi (1D), yaitu gambaran tahanan jenis lapisan-lapisan bawah permukaan tanah dan tidak menggambarkan secara lateral (2D), sehingga interpretasi akan terbatas dan sebaran lapisan akuifer bawah permukaan tidak terlihat. Hal ini biasanya di karenakan keterbatasan alat yang digunakan dan pertimbangan efesiensinya. Pada penelitian ini dengan menggunakan alat Resistivitymeter Supersting Rl/IP dapat mengukur tahanan jenis dengan hasil analisa berupa 2 dimensi (2D); konfigurasi wenner dan wenner-schlumberger yang hasil kedua konfigurasi tersebut akan saling dibandingkan. Hasil analisa berupa gambaran 2 dimensi bawah permukaan tanah akan lebih mudah menginterpretasikan sebaran akuifer dan penentuan titik lokasi pengeboran nantinya.

\section{Konfigurasi Wenner}

Diantara beberapa konfigurasi pada metode geolistrik, wenner memiliki kekuatan sinyal terkuat. Hal ini sangat membantu jika survei dilakukan di area dengan noise yang tinggi. Keunggulan dari konfigurasi wenner, yaitu relatif sensitif terhadap perubahan vertikal dalam resistivitas bawah permukaan tanah. Namun, kurang sensitif terhadap perubahan horizontal resistivitas bawah permukaan. Secara umum, Wenner bagus dalam pendeteksian perubahan vertikal (yaitu struktur horizontal), tetapi relatif tidak sensitif dalam mendeteksi perubahan horizontal (yaitu struktur vertikal yang sempit).

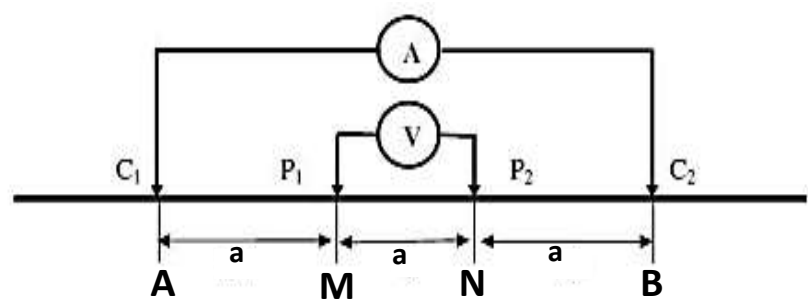

\section{Gambar 4. Pengaturan Elektroda Konfigurasi Wenner}

Susunan elektroda akuisisi data konfigurasi wenner dapat dilihat pada gambar 4, dimana masing-masing jarak elektroda pada setiap titik pengukuran memiliki nilai yang sama.

Faktor geometri dari konfigurasi wenner adalah :

$K=2 \pi a$

dengan $a$ adalah jarak antara elektroda. 


\section{Konfigurasi Wenner-schlumberger}

Konfigurasi ini merupakan gabungan antara Wenner dan Schlumberger dimana cukup sensitif terhadap horizontal (untuk nilai "n" rendah) dan struktur vertikal (untuk nilai "n" tinggi). Kekuatan sinyal lebih lemah dari Wenner-schlumberger, sehingga menjadi pertimbangan jika survei dilakukan di area dengan noise yang tinggi.

Konfigurasi ini adalah konfigurasi dengan sistem aturan spasi yang konstan dengan catatan faktor pembanding " $n$ " untuk konfigurasi ini adalah perbandingan jarak antara elektroda AM dengan jarak antara MN seperti pada Gambar 5. Jika jarak antara elektroda potensial MN adalah a maka jarak antar elektroda arus (Adan B) adalah 2na + a.

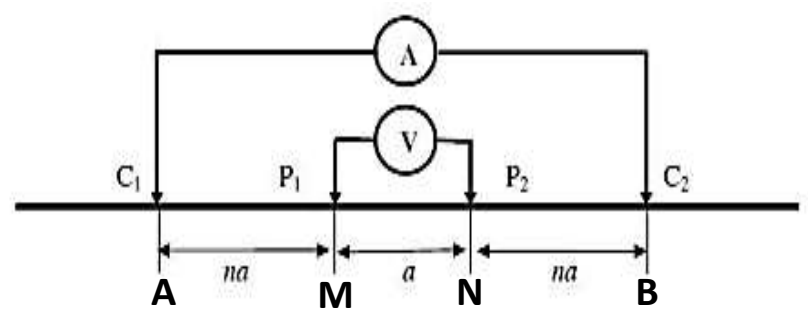

Gambar 5. Pengaturan Elektroda Konfigurasi Wenner-schlumberger

Susunan elektroda akuisisi data konfigurasi Wennerschlumberger dapat dilihat pada gambar 5, dimana masing-masing jarak elektroda pada setiap titik pengukuran memiliki nilai yang berbeda.

Faktor geometri dari konfigurasi Wennerschlumberger adalah :

$\boldsymbol{K}=\boldsymbol{n}(\boldsymbol{n}+\mathbf{1}) \boldsymbol{\pi} \boldsymbol{a}$

dengan $a$ adalah jarak antara elektroda $\mathrm{M}$ dan $\mathrm{N}$ (Utiya, dkk, 2015).

Data tahanan jenis yang diperoleh di masingmasing titik pengukuran masih bersifat semu dan akan dikonversi ke tahanan jenis sebenarnya setelah dikalikan dengan nilai faktor geometri (K); konfigurasi wenner terhadap persamaan 4 dan konfigurasi wenner-schlumberger terhadap persamaan 5. Pada penelitian ini, proses tersebut sudah dilakukan secara otomatis di dalam perangkat alat resistivitymeter yang digunakan.

\section{Resistivitas (Tahanan Jenis) Air Tanah}

Salah satu metode survei Geofisika yang lazim digunakan untuk penelitian sumber air tanah adalah metode Geolistrik Tahanan Jenis. Metode ini memanfaatkan keragaman nilai resistivitas batuan bawah permukaan untuk mendeteksi struktur geologi atau formasi batuan bawah permukaan, sehingga dapat diterapkan untuk menduga keberadaan akuifer air tanah (Priyantari dan Wahyono, 2005).Potensi keberadaan air tanah dapat diketahui dengan mengidentifikasi formasi batuan dan struktur bawah permukaan berdasarkan variasi nilai resistivitas (Wijaya, 2015).

Pada gambar 6 di atas, menunjukkan rentang tahanan jenis beberapa bahan. Tahanan jenis air tanah bervariasi dari 10 hingga 100 ohm.m, tergantung pada konsentrasi garam terlarut di dalamnya. Perhatikan tahanan jenis rendah (sekitar 0,2 ohm.m) air laut karena kandungan garam yang relatif tinggi. Ini menjadikan metode tahanan jenis ini sebagai teknik yang ideal untuk memetakan salinitas dan muka air tawar di daerah pesisir (Loke, 2004).

\section{HASIL DAN PEMBAHASAN}

Penentuan zona akuifer air tanah kurang akurat jika hanya berdasarkan rentang nilai tahanan jenis seperti pada gambar 6. Hal ini dikarenakan pada rentang nilai tersebut banyak kemungkinan nilai tahanan jenis bahan lain yang terdeteksi seperti alluvium, clay, lignite, dan lainnya. Maka sebagai data pendukung, diperlukan data geologi dan data hidrogeologi di daerah penelitian, sehingga hasil interpretasi akan lebih akurat.

\section{Geologi Daerah Penelitian}

Lintasan geolistrik berada pada pinggiran formasi tanjung dan hampir bersinggungan dengan formasi pitap. Secara geologi daerah pengukuran tersusun oleh satuan batuan sedimen Formasi Tanjung (tanda silang merah pada gambar 7). Formasi ini disusun oleh batu pasir kuarsa dan batu lempung dengan sisipan batubara. Setempat bersisipan dengan batu gamping yang mengandung fosil yang menunjukkan umur Eosen. Diendapkan dalam lingkungan fluviatil sampai dengan laut dangkal, dengan ketebalan sekitar $750 \mathrm{~m}$.

\section{Hidrogeologi Daerah Penelitian}

Berdasarkan litologi-litologi penyusun formasi di daerah penelitian, lapisan batuan yang berpotensi menjadi akuifer adalah batu pasir kuarsa dan batu bara Formasi Tanjung, serta hasil lapukan batuan. Sedangkan batu lempung dari Formasi Tanjung, berpotensi menjadi akuitar (penyekat). 


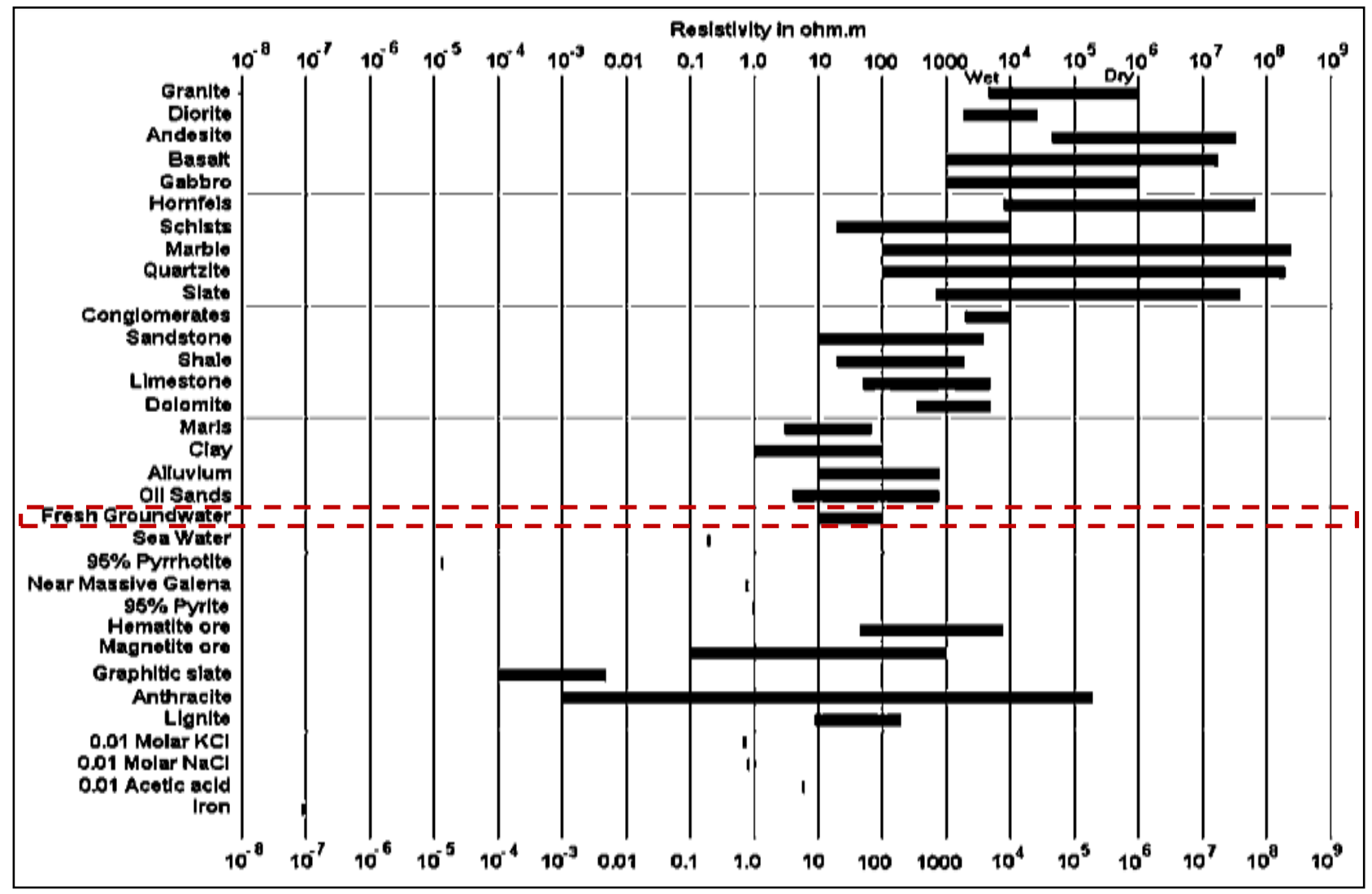

Gambar 6. Tahanan Jenis beberapa Batuan,

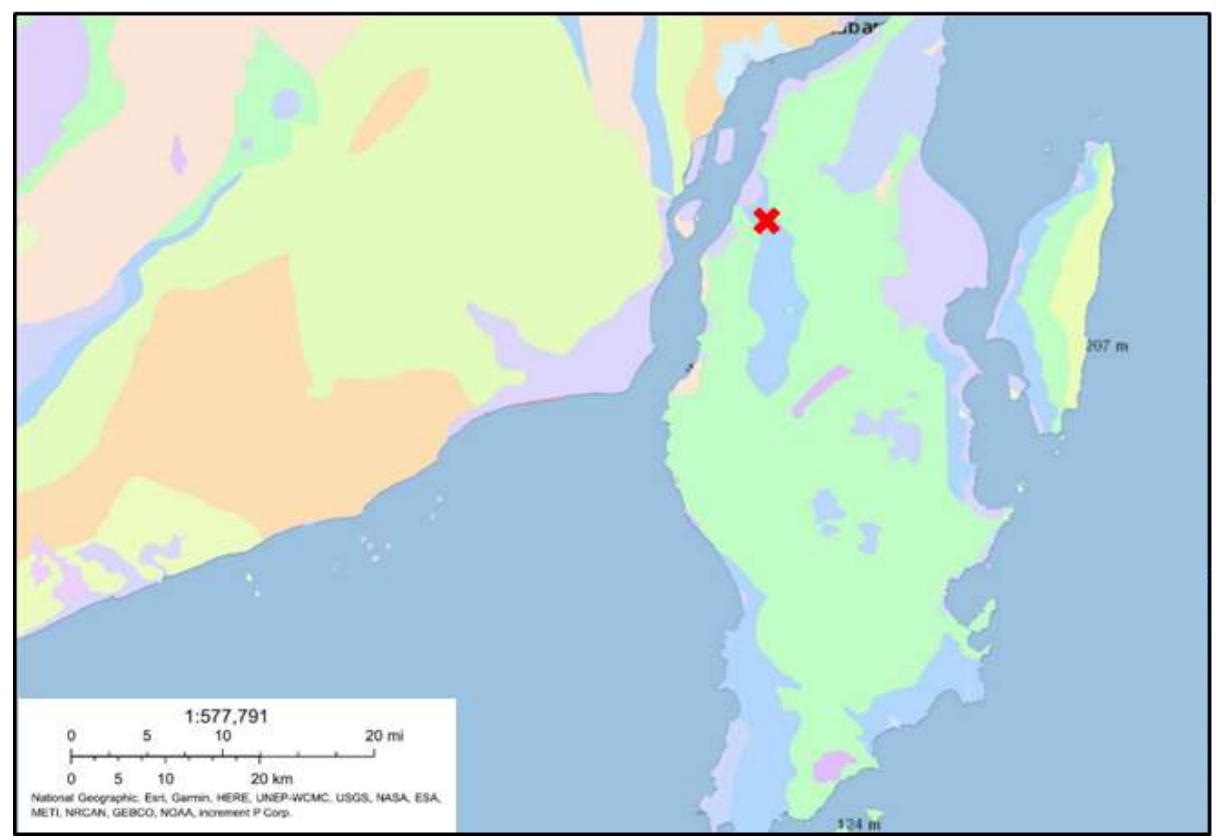

\begin{tabular}{|l|}
\hline Geologi Litologi \\
\hline Alluvium Deposit \\
\hline Batukora Unit \\
\hline Berai Formation \\
\hline Birang Formation \\
\hline Dahor Formation \\
\hline Diorite \\
\hline Early Cretaceous Gabbro \\
\hline Early Cretaceous Metamorphic Rock \\
\hline Haruyan Formation \\
\hline Jagoi Granodiorite \\
\hline Jurrasic Ophiolit \\
\hline Tanjung Formation \\
\hline Longbawan Formation \\
\hline Manunggul Formation \\
\hline Paau Formation \\
\hline Pitap Formation \\
\hline
\end{tabular}

Gambar 7. Peta Geologi Daerah Penelitian (Pusdatin ESDM, 2020)

Secara hidrogeologi regional daerah produktifitasnya, akuifer termasuk dalam pengukuran termasuk dalam daerah dengan akuifer produktifitas kelulusan air rendah dengan debit aliran antar butir sebagian merupakan aliran antar maksimal 5 liter/detik (tanda silang hitam pada celah atau sarang. Berdasarkan sebaran gambar 8). 


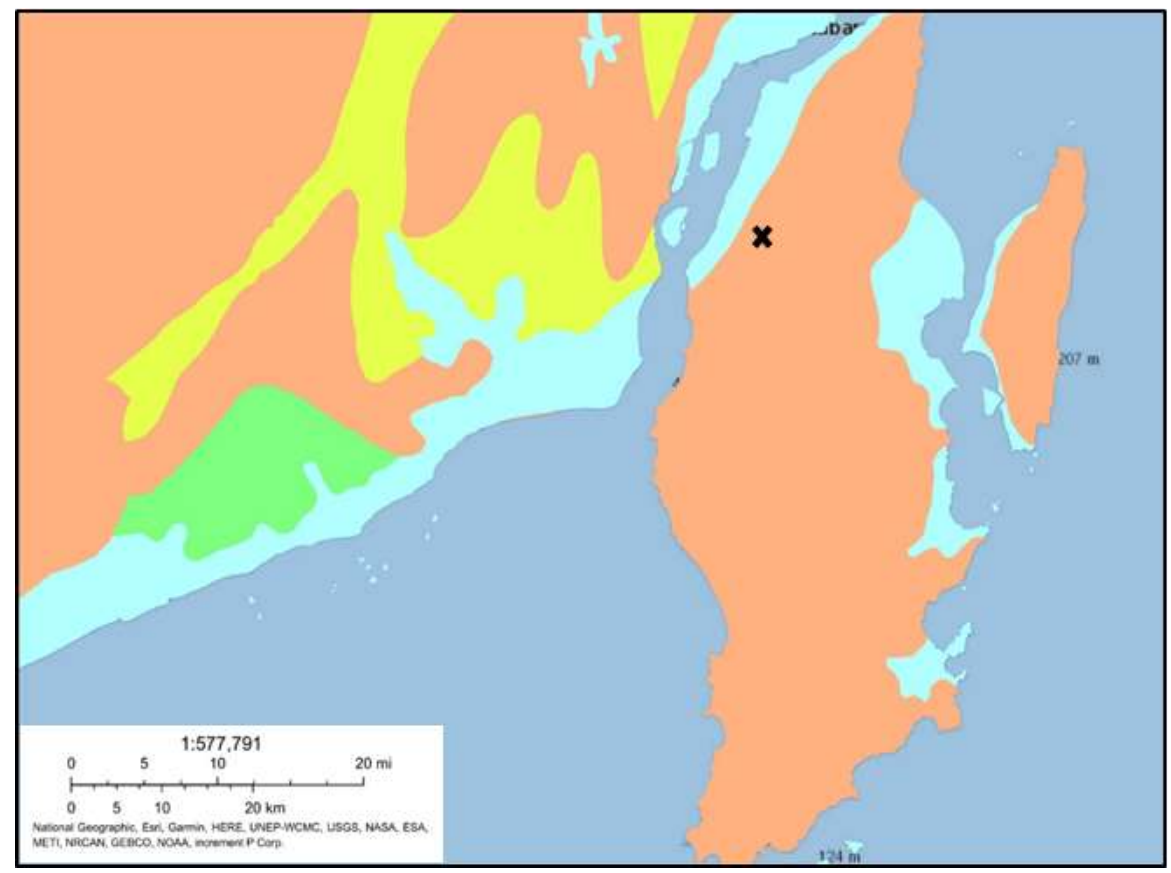

Produktivitas Akuifer

Akuifer dengan Aliran Melalui Ruang Antarbutir (Akifer produktif dengan penyebaran luas)

Akuifer dengan Aliran Melalui Celahan dan Ruang Antarbutir (Akifer produktif sedang dengan penyebaran luas)

Akuifer dengan Aliran Melalui Ruang Rekahan dan Saluran (Setempat, akuifer produktif)

Akuifer (Bercelah atau Sarang) Produktif kecil dengan Airtanah Langka (Akuifer produktif kecil)

Gambar 8. Peta Produktivitas Akuifer Daerah Penelitian (Pusdatin ESDM, 2020)

\section{Komparasi Konfigurasi}

kedua konfigurasi yang digunakan masingmasing meiliki kelebihan dan kekurangan, sehingga saling menutupi kelemahan masing-masing konfigurasi. Penggunaan dua konfigurasi bertujuan sebagai data pembanding dari hasil analisa akhir atau penampang 2 dimensi tahanan jenis bawah permukaan tanah, dengan harapan hasil analisa akhir kedua konfigurasi tidak jauh berbeda. Adanya perbedaan hasil penampang yang signifikan, menandakan kemungkinan besar ada kesalahan pada akuisisi data.

Pada gambar 9 dan gambar 10 merupakan hasil analisa akhir kedua konfigurasi. Jika dilihat dari RMS (Root Mean Square), konfigurasi wennershlumberger memiliki nilai RMS 2,35\% sedangkan konfigurasi wenner memiliki nilai RMS 1,77\%. Artinya, konfigurasi wenner memiliki nilai error yang lebih rendah dan akurasinya lebih tinggi. Hal ini sesuai dengan kelebihan dari konfigurasi wenner yang memiliki signal lebih kuat dibandingkan dengan konfigurasi lainnya pada metode geolistrik, khususnya untuk penampang 2 dimensi, sehingga dapat menekan noise (signal pengganggu) bawah permukaan di daerah penelitian. Sedangkan untuk konfigurasi wenner-shlumberger kurang baik dalam menekan noise yang ada. Secara visual menampakkan pola warna sebagai gambaran nilai tahanan jenis batuan bawah permukaan yang mana memiliki kenampakan penampang yang sama, meskipun ada beberapa perbedaan pola di beberapa lokasi.

\section{Zona Potensi Air Tanah}

Dari penampang tahanan jenis, didapatkan nilai yang paling rendah $20 \Omega \mathrm{m}$ yang paling tinggi 317 $\Omega \mathrm{m}$ untuk konfigurasi wenner-schlumberger, demikian juga untuk konfigurasi wenner.

Secara keseluruhan berdasarkan penampang dua dimensi nilai tahanan jenis lintasan geolistrik baik dengan konfigurasi Wenner-schlumberger (Gambar 9) maupun konfigurasi wenner (gambar 10) maka dapat diinterpretasikan bahwa batuan yang menyusun Desa Selaru Kecamatan Pulau Laut Tengah terdiri dari 2 (dua) satuan batuan. Satuan batuan pertama adalah satuan batuan Formasi Tanjung yang terdiri dari batupasir kuarsa dan batu lempung dengan sisipan batubara. Nilai tahanan jenis satuan ini $\leq 120$ Ohm.m. Sifat hidrolikanya dengan porositas besar dan permeabilitas kecil serta potensi air tanah pada satuan batuan ini kecil. Posisi satuan batuan ini berada dipermukaan tanah hingga berkisar kekedalaman $40 \mathrm{~m}$. Pada penampang tahanan jenis, satuan ini berwarna biru tua - biru 


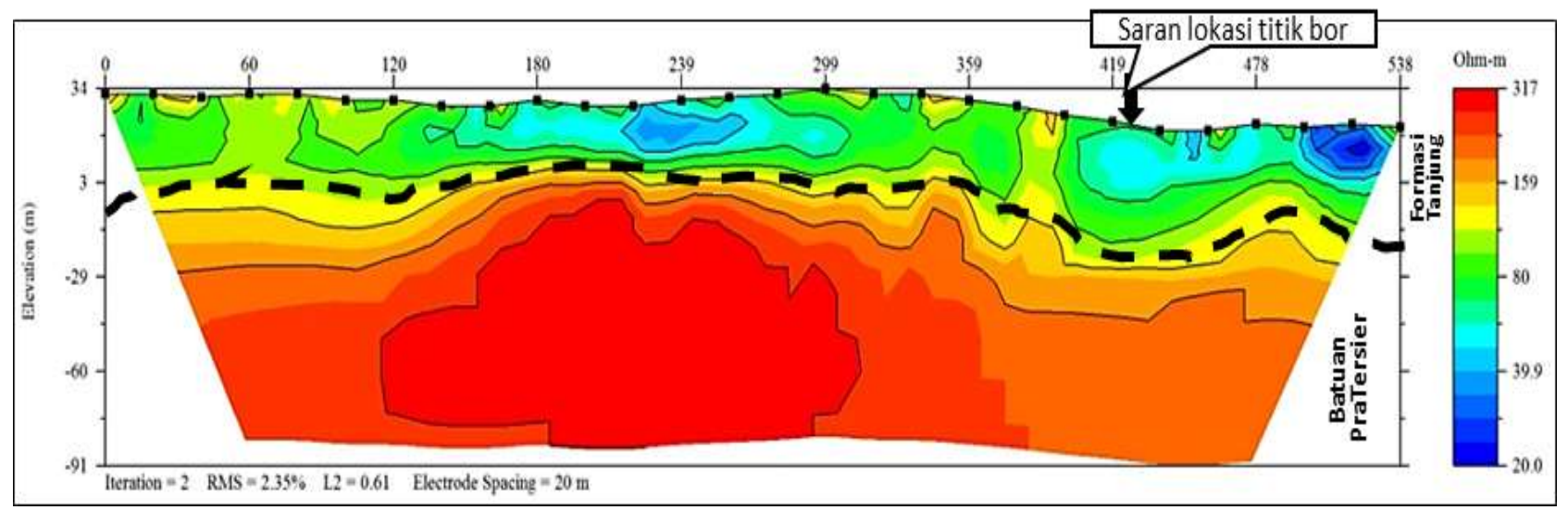

Gambar 9. Penampang geolistrik 2D Konfigurasi Wenner-Shlumberger

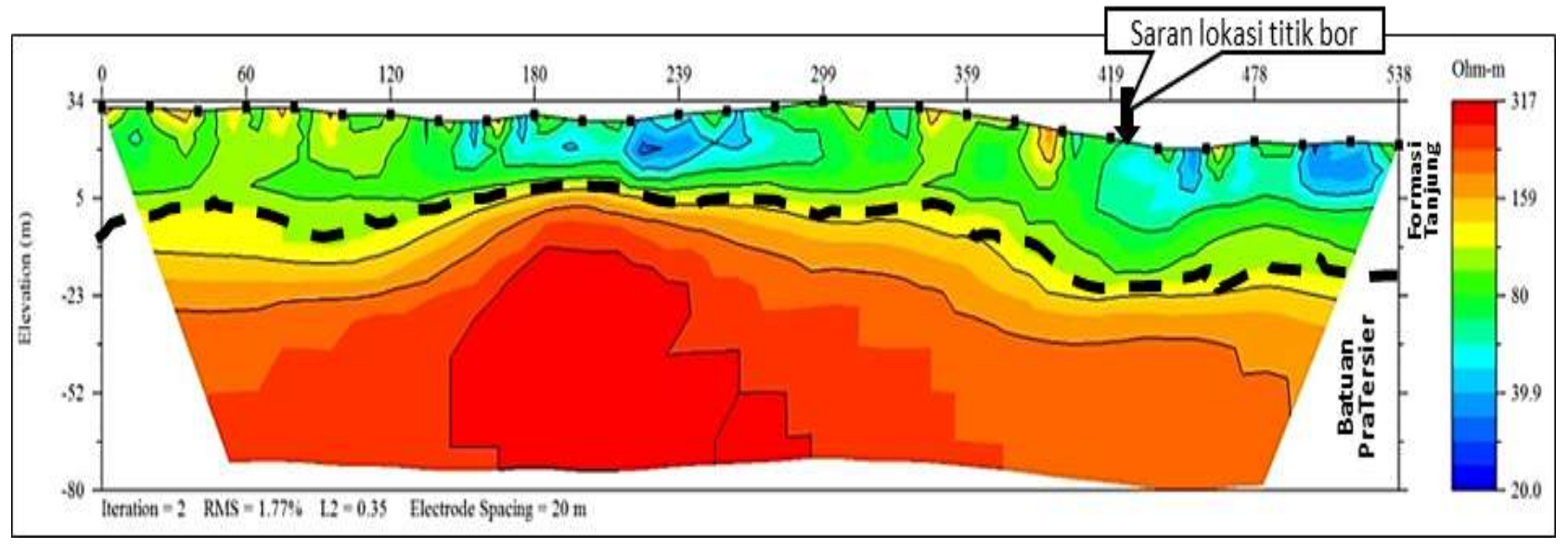

Gambar 10. Penampang geolistrik 2D Konfigurasi Wenner

muda dan hijau kekuningan. Batupasir kuarsa yang kemungkinan menjadi akuifer aliran antar butir yang memiliki permeabilitas rendah dan batuan lempung sebagai lapisan akuitarnya dengan sisipan batubara (akuifer aliran antara rekahan atau celah). Adanya batuan lapukan kemungkinan dapat menjadi akuifer jenis bersarang dikarenakan sifat lapukan pada batuan yang tidak sama di setiap lapisan atau bahkan kemungkinan membentuk zona lapukan spot-spot. Dalam hal eksploitasi air tanah secara berkelanjutan, akuifer batupasir kuarsa adalah lebih baik. Dari penampang 2 dimensi tahanan jenis memberikan informasi kedalaman ideal akuifer yaitu 40 meter dari permukaan. Meskipun demikian, untuk informasi detailnya perlu dilakukan well logging setelah pengeboran.

Satuan batuan kedua yang menyusun lintasan ini adalah satuan batuan PraTersier yang terdiri dari batuan sedimen dan batuan vulkanik dengan sifat fisik batuan keras dan massif. Nilai tahanan jenis $\geq$ $120 \mathrm{Ohm}$ meter dengan sifat hidrolika berupa porositas sangat kecil dan permeabilitas sangat kecil, kecuali porositas sekunder pada kekar-kekar batuan, sehingga pada lapisan batuan ini potensi air satuan tanahnya kecil. Pada penampang tahanan jenis ini berwarna kuning - merah dengan kedalaman $>40$ meter dibawah permukaan.

Hal ini sesuai data Pusdatin ESDM tahun 2020 yang menyatakan di daerah penelitian merupakan daerah akuifer bercelah atau sarang dengan produktivitas kecil bahkan airtanah langka. Sehingga secara umum dapat dikatakan bahwa daerah pengukuran, potensi air tanahnya kecil dengan debit $\leq 5$ liter/detik. Meskipun debitnya kecil, hal ini dapat dimanfaatkan mengingat daerah Desa Selaru merupakan daerah yang sulit 
memperoleh air bersih Titik bor ideal untuk pemanfaatan air tanah adalah pada posisi elektroda ke 21 atau sekitar 420 meter dari titik awal lintasan geolistrik (pada Gambar 9 dan 10). Penentuan ini didasari pada sebaran penampang lapisan-lapisan yang terbentuk, dimana pada posisi tersebut lapisan yang diduga akuifer terdapat pada zona lapisan yang paling rendah posisinya terhadap lainnya, sehingga aliran air akan menuju ke zona tersebut. Selain hal tersebut, lokasi saran titik bor tersebut lebih dekat dengan pemukiman penduduk, sehingga aksesnya akan lebih dekat.

\section{KESIMPULAN}

Hasil Pengamatan lapangan dan interpretasi penampang 2 dimensi tahanan jenis di lokasi penelitian maka didapatkan beberapa simpulan sebagai berikut :

1. Penampang tahanan jenis diinterpretasikan adanya dua satuan batuan yaitu satuan batuan Formasi Tanjung dengan nilai tahanan jenis $\leq$ $120 \mathrm{ohm}$ meter dan satuan batuan PraTersier dengan nilai tahanan jenis $\geq 120 \Omega \mathrm{m}$.

2. Kedalaman ideal akuifer adalah 40 meter bawah permukaan dengan lapisan akuifer berupa batupasir kuarsa dan batu lempung dengan sisipan batubara sebagai akuitar.

3. Posisi titik bor terletak pada elektroda ke 21 atau sekitar 420 meter dari posisi awal lintasan pengukuran.

4. Potensi airtanah di lokasi penelitian Desa Selaru kecil bahkan airtanah langka dengan debit $\leq 5$ liter/detik.

\section{Saran}

Mengingat kondisi geologi dan hidrogeologi serta hasil pengukuran tahanan jenis yang sudah dijelaskan diatas maka disarankan agar:

1. Perlu penambahan titik ukur lintasan geolistrik yang lain di daerah penelitian sebagai data pembanding.

2. Perlu adanya koreksi terhadap data well logging, agar interpretasi lebih detail terhadap posisi akuifer yang dihasilkan sehingga lebih akurat.

\section{DAFTAR PUSTAKA}

Bisri, Mohammad. 1991. Aliran Air Tanah. Malang. Fakultas Teknik Universitas Brawijaya.
Loke, M.H. 2004. Tutorial : 2-D and 3-D electrical imaging surveys.

Priyantari dan Wahyono. 2005. Penentuan Bidang Gelincir Tanah Longsor Berdasar Sifat Kelistrikan Bumi. Jurnal Ilmu Dasar 6(2):137141.

Pusat Data dan Informasi E.S.D.M. (Pusdatin ESDM), 2020. E.S.D.M. One Map: Exploring Energy and Mineral Resources of Indonesia. https://geoportal.esdm.go.id

Utiya, J., As'ari., Seni H.J.T. 2015. Metode Geolistrik Resistivitas Konfigurasi Wennerschlumberger dan Konfigurasi Dipole-dipole untuk Identifikasi Patahan Manado di Kecamatan Paaldua Kota Manado. Jurnal Ilmiah Sains Vol. 15 No. 2, Oktober 2015.

Wijaya, A. S. 2015. Aplikasi Metode Geolistrik Resistivitas Konfigurasi Wennerschlumberger Untuk Menentukan Struktur Tanah di Halaman Belakang SCC ITS Surabaya. Jurnal Fisika Indonesia, 119(55): 15 